\title{
CHEYNE-STOKES RESPIRATION IN PATIENTS WITH CONGESTIVE HEART FAILURE: CAUSES AND CONSEQUENCES
}

Lorenzi-Filho G, Genta PR, Figueiredo AC, Inoue D. Cheyne-Stokes respiration in patients with congestive heart failure: causes and consequences. Clinics. 2005;60(4): 333-44.

Cheyne-Stokes respiration is a form of periodic breathing in which central apneas and hypopneas alternate with periods of hyperventilation, producing a waxing and waning pattern of tidal volume. This review focuses on the causes and consequences of Cheyne-Stokes respiration in patients with congestive heart failure, in whom the prevalence is strikingly high and ranges from $30 \%$ to $50 \%$. Several factors have been implicated in the genesis of Cheyne-Stokes respiration, including low cardiac output and recurrent hypoxia. The key pathophysiological mechanism triggering Cheyne-Stokes respiration is hyperventilation and low arterial $\mathrm{CO}_{2}\left(\mathrm{PaCO}_{2}\right)$ that when below the apneic threshold triggers a central apnea. Hyperventilation is associated with pulmonary congestion, and Cheyne-Stokes respiration is more prone to occur during sleep, when the respiratory system is mainly dependent on chemical control. It is associated with recurrent dips in oxygen saturation and arousals from sleep, with oscillations in blood pressure and heart rate, sympathetic activation and increased risk of ventricular tachycardia. Cheyne-Stokes respiration is an independent marker of poor prognosis and may participate in a vicious cycle, further stressing the failing heart.

\section{KEYWORDS: Cheyne-Stokes respiration. Congestive heart failure. Sleep. Control of breathing. Central apnea.}

Clinicians generally pay little attention to a patient's pattern of breathing. ${ }^{1}$ This is partly the result of the limitations of physical examination, which is notoriously unreliable in assessing changes in tidal volume. ${ }^{2}$ Therefore, detection of abnormal patterns requires either an unusually practiced eye or, preferably, an objective method of recording the breathing pattern. Moreover, subtle alterations in the breathing pattern may manifest themselves only during exercise ${ }^{3}$ or sleep. ${ }^{4}$ Cheyne-Stokes respiration (CSR) is the best-known disturbance of the breathing pattern. ${ }^{1}$ The periodic irregularity of respiration, characterized by a period of apnea followed by breathing that begins almost imperceptibly, waxes until it becomes dyspneic then wanes

Sleep Laboratory, Pulmonary Division, Heart Institute (InCor), Faculty of Medicine, University of São Paulo - São Paulo/SP, Brazil.

E-mail: geraldo.lorenzi@incor.usp.br

Received for publication on May 06, 2005.

Accepted for publication on May 11, 2005. until apnea follows the last shallow breath, was first described by Cheyne, in $1818 .^{5}$ This particular pattern of breathing was later recognized as a complication associated with heart failure by Stokes, in $1854 .^{6}$ The patient in the original description suffered from both congestive heart failure (CHF) and neurologic disease. ${ }^{5}$ Therefore, the term Cheyne-Stokes respiration has been used to describe this abnormal pattern of breathing but not to denote any specific underlying etiology. It is also not clear from the original descriptions whether the apneas were central or obstructive in nature (ie, absence or presence of respiratory effort during apnea, respectively). Patients with CHF may present both central and obstructive sleep apnea, ${ }^{7-15}$ may convert obstructive to central sleep apnea during a single night, ${ }^{16}$ and may present obstructive apneas with a prolonged ventilatory pattern that mimics Cheyne-Stokes respiration. ${ }^{17}$ In this text for the sake of simplicity, unless otherwise stated, Cheyne-Stokes respiration will imply that it is associated with central apnea (Fig. 1). 


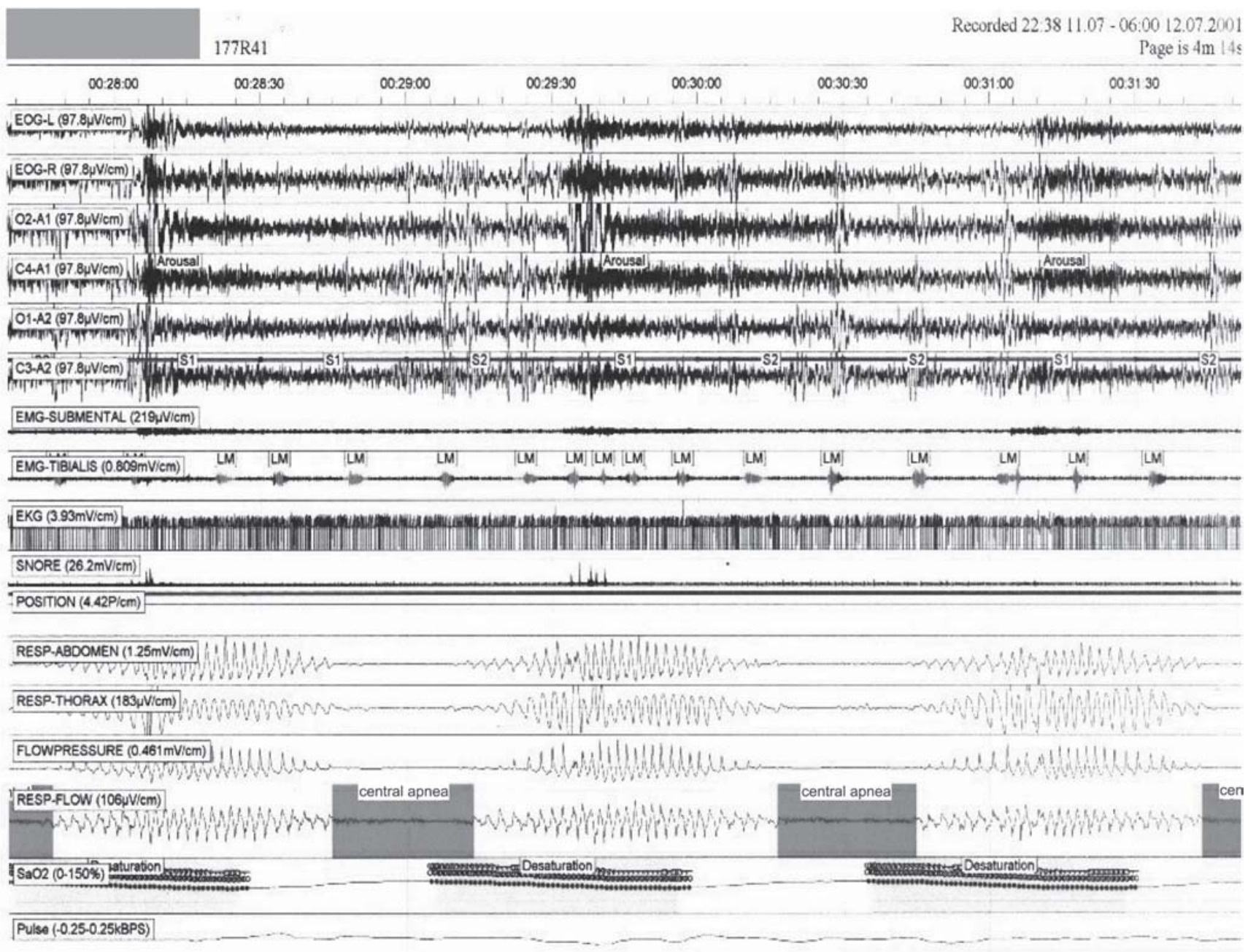

Figure 1 - Polysomnographic recordings of a congestive heart failure presenting Cheyne-Stokes respiration during sleep. The top channels are related to sleep recordings. The bottom channels trac respiration by monitoring motion of the thorax, abdomen and respiratory flow (nasal canula). Observe the typical crescendo-decrescendo tidal volume interposed with central apneas

Cheyne-Stokes respiration has for too long been considered as a physiologic curiosity and not a clinical problem worthy of diagnosis and specific therapy, ${ }^{4,7}$ and only in the last few years has it attracted more clinical attention, since it has been recognized to be very common among patients with severe but stable $\mathrm{CHF}$, and it can cause symptoms of a sleep apnea syndrome. ${ }^{4,7-13}$ In patients with severe but stable CHF, Cheyne-Stokes respiration is present in $30 \%$ to $50 \%$ of the patients. ${ }^{13,14}$ It is present in CHF of all origins, including Chagas disease. ${ }^{14,15}$ There is increasing evidence to suggest that Cheyne-Stokes respiration in patients with CHF participates a vicious cycle that further stresses the failing heart. In line with this hypothesis, we have shown that periodic oscillations of ventilation in normal subjects promoted profound oscillations in blood pressure and heart rate ${ }^{18}$ similar cardiovascular effects were present in CHF patients during Cheyne-Stokes respiration ${ }^{19}$; and periodic ventricular premature beats were found to be higher during periods of this respiration than during periods of regular breathing in CHF patients. ${ }^{20} \mathrm{We}$ have also recently reported that a mild form of Cheyne-Stokes respiration, characterized by periodic and cyclic oscillations of minute ventilation (also known as periodic breathing) was present in $30 \%$ of a population of CHF patients evaluated for heart transplant and was a powerful predictor of mortality. ${ }^{3}$ These findings may help to explain the increased mortality observed in CHF patients presenting Cheyne-Stokes respiration observed in some studies. ${ }^{21-23}$ This review will focus on the causes and consequences of Cheyne-Stokes respiration in patients with CHF. We will also briefly review concepts concerning the control of breathing. More extensive reviews on this topic have been recently published. ${ }^{4,24-27}$ 


\section{CONTROL OF BREATHING}

The respiratory and the cardiovascular systems act in concert to transfer oxygen $\left(\mathrm{O}_{2}\right)$ and carbon dioxide $\left(\mathrm{CO}_{2}\right)$ between the atmosphere and the cells. Their control systems must be integrated to ensure that the metabolic needs of the tissues are met under varying conditions according to demands. ${ }^{28}$ Under normal conditions, ventilation is stable and maintains arterial blood gas tensions within narrow limits through a negative feedback circuit. This negative feedback system consists of a central controller sensitive to fluctuations in $\mathrm{PaO}_{2}$ and $\mathrm{PaCO}_{2}$ at the peripheral and central chemoreceptors and a mechanism (the lungs, chest wall, and respiratory muscles) that generates ventilation. ${ }^{29,30}$ The controlled variables are $\mathrm{PaO}_{2}, \mathrm{PaCO}_{2}$, and $\mathrm{pH}$, which act as negative feedback signals to the central controller. In turn, the central controller maintains blood gas homeostasis by altering its neural output to the respiratory muscles in order to move the chest wall to achieve the appropriate level of ventilation. $\mathrm{PaO}_{2}$ and $\mathrm{PaCO}_{2}$ are altered accordingly. The system is stable, and the responses are linear over a wide range of $\mathrm{PaCO}_{2}$. However, apnea may prevail when the $\mathrm{PaCO}_{2}$ is driven below the apneic threshold. ${ }^{29}$ On the other hand, blood gas homeostasis is maintained through certain stabilizing influences inherent in the system. These include the maintenance of $\mathrm{PaCO}_{2}$ well above the threshold for apnea, a relatively low gain of the chemoreceptors, a short delay in the transmission of the effects of ventilation on $\mathrm{PaO}_{2}$ and $\mathrm{PaCO}_{2}$ to the chemoreceptors, the rapid correction of deviations in blood gas tensions toward the desired level, and a high functional residual capacity acting as a large reservoir of $\mathrm{O}_{2}$ and $\mathrm{CO}_{2}$ within the body to damp oscillations in $\mathrm{PaO}_{2}$ and $\mathrm{PaCO}_{2}$ during apneas. ${ }^{24,25,29,30}$

During sleep, the respiratory system is particularly prone to instability. As one passes from wakefulness to nonrapid eye movement (NREM) sleep, the waking neural drive to breathe is abolished, and the behavioral control system becomes quiescent. Therefore, the nonchemical drive to breathe associated with wakefulness, which tends to maintain ventilation even when $\mathrm{PaCO}_{2}$ is driven below the apnea threshold, is lost during sleep and breathing becomes critically dependent on the metabolic control system. ${ }^{29-32}$ In addition, during NREM sleep the threshold for a ventilatory response to $\mathrm{CO}_{2}$ is increased, so that a higher $\mathrm{PaCO}_{2}$ is necessary to stimulate breathing as compared to the awake state. ${ }^{28,29}$ If the $\mathrm{PaCO}_{2}$ during wakefulness is below this new threshold level during sleep, there will be a loss of respiratory drive resulting in a central apnea in the transition awake-sleep. During apnea, $\mathrm{PaCO}_{2}$ rises (at a rate proportional to metabolic $\mathrm{CO}_{2}$ production) until it reaches the critical threshold value, and breathing resumes. If sleep becomes firmly established at this point, regular breathing follows. ${ }^{29}$ However, should the central nervous system state shift back momentarily to the awake state, as occurs during arousals from sleep, the increased $\mathrm{PaCO}_{2}$ level that was present during sleep now represents a state of relative hypercapnia for wakefulness. Accordingly, a period of hyperpnea follows, in accordance with the awake ventilatory response to $\mathrm{CO}_{2}$, resulting in the hyperpneic phase of periodic breathing. As long as the central nervous system state continues to fluctuate between wakefulness and sleep, waxing and waning of the waking neural drive results in alternating periods of hyperpnea and apnea until sleep becomes firmly established. Hence, transitions in sleep-wakefulness states are an ideal setting for the generation of respiratory instability and periodic breathing even in normal humans. ${ }^{33}$ Similarly, sleep-awake transitions may produce respiratory control instability by a different mechanism: upper airway instability. Sleep is associated with loss of muscle tone, rendering the upper airway prone to collapse. In patients with partial or complete airway collapse at sleep, a central neural output to the respiratory muscles will not be rapidly translated into airflow. As a consequence, ventilation may be not sufficient during periods of upper airway collapse and, a moment later, will overshoot during brief arousals (when upper airway patency is reestablished). This mechanism may also lead to fluctuations of $\mathrm{PaCO}_{2}$ above and below the apneic threshold..$^{30}$

\section{CAUSES OF CHEYNE-STOKES RESPIRATION}

The key pathophysiologic mechanism leading to Cheyne-Stokes respiration is a fluctuation of $\mathrm{PaCO}_{2}$ above and below the apneic threshold. ${ }^{4,7,24,25}$ In patients with $\mathrm{CHF}$, a number of destabilizing factors contribute to fluctuation in $\mathrm{PaCO}_{2}$. First, a low $\mathrm{PaCO}_{2}$ close to apneic predisposes to the development of central apneas. Under this condition, a relatively small increase in ventilation would drive $\mathrm{PaCO}_{2}$ below threshold and trigger a central apnea. ${ }^{4,7,24,25,34}$ Naughton et al. ${ }^{35}$ and Hanly et al. ${ }^{36}$ have shown that CHF patients with Cheyne-Stokes respiration have lower $\mathrm{PaCO}_{2}$ both while awake and asleep than those without CheyneStokes. In patients with $\mathrm{CHF}$, an association between Cheyne-Stokes and low $\mathrm{PaCO}_{2}$ both during wakefulness and NREM sleep has been demonstrated in several reports. ${ }^{35-40}$ Naughton et al. ${ }^{35}$ found that CHF patients with CheyneStokes respiration had lower $\mathrm{PaCO}_{2}$ during wakefulness and NREM sleep than patients without it, who had comparable age, $\mathrm{LVEF}, \mathrm{PaO}_{2}$, and lung-to-chemoreceptor circulatory delay. All episodes of Cheyne-Stokes respiration starting during stage 2 sleep were almost always, precipitated by hy- 
perventilation in association with arousals from sleep. Furthermore, during Cheyne-Stokes episodes in stage 2 sleep, $\mathrm{PaCO}_{2}$ fell on average by $1.5 \mathrm{~mm} \mathrm{Hg}$, which mirrored a $23 \%$ rise in minute ventilation. ${ }^{35}$

Patients with CHF and Cheyne-Stokes respiration have an unusual response to the sleeping state, in that their $\mathrm{PaCO}_{2}$ levels do not increase as they go from wakefulness to sleep, ${ }^{38,39}$ and as a consequence $\mathrm{PaCO}_{2}$, is closer to their apneic threshold during sleep. ${ }^{39}$ Lorenzi-Filho et al. ${ }^{40}$ were able to abolish Cheyne-Stokes in CHF patients by inhalation of small concentrations of $\mathrm{CO}_{2}$ delivered by a mask. Stabilization of breathing was achieved by a small ( $2 \mathrm{~mm}$ $\mathrm{Hg}$ ) but significant increase in transcutaneous $\mathrm{PCO}_{2}$. In contrast, supplemental oxygen was not able to raise transcutaneous $\mathrm{PCO}_{2}$ and had no significant impact on the frequency of Cheyne-Stokes. ${ }^{40}$ This study reveals the critical importance of small variations in $\mathrm{PaCO}_{2}$, which when it falls below the apneic threshold triggers central apneas and Cheyne-Stokes respiration. Arousals, through promotion of hyperventilation, appear to facilitate rather than to provoke periodic breathing directly.

The second question is: why do patients with $\mathrm{CHF}$ hyperventilate? Several possible mechanisms, listed in Table 1 and summarized in Figure 2, may participate. The most important mechanisms will be discussed below.

Table 1 - Mechanisms responsible for respiratory stability (STABLE) and instability (UNSTABLE) in congestive heart failure patients

\begin{tabular}{lcl}
\hline Variable & $\begin{array}{c}\text { VENTILATION } \\
\text { STABLE }\end{array}$ & UNSTABLE \\
\hline PaCO $_{2}$ (apneic threshold) & Above & Close \\
Chemoreflex response & $\begin{array}{l}\text { Rapid } \\
\text { Adequate }\end{array}$ & $\begin{array}{l}\text { Delayed } \\
\text { Increased }\end{array}$ \\
$\mathrm{O}_{2}$ and $\mathrm{CO}_{2}$ reservoir & Large & $\begin{array}{l}\text { Low Functional } \\
\text { Residual Capacity }\end{array}$ \\
\hline & SLEEP FACTORS & \\
\hline Awake drive to breathe & Present & Absent during sleep \\
Continuity of sleep & Present & Arousals \\
\hline
\end{tabular}

\section{Pulmonary congestion}

There is a considerable body of evidence showing that pulmonary congestion is associated with reduced $\mathrm{PaCO}_{2}$. Tkacova et al. ${ }^{38}$ examined a population of patients with CHF due to nonischemic dilated cardiomyopathy and showed that, in spite of similar left ventricular ejection fractions, the left ventricular (LV) end diastolic and systolic volumes were twice as high in patients with Cheyne-Stokes respiration as compared to those without it. In addition, Cheyne-Stokes patients had a significantly lower $\mathrm{PaCO}_{2}$ while awake, and a lower mean transcutaneous $\mathrm{CO}_{2}$ $\left(\mathrm{PtcCO}_{2}\right)$ during stage 2 sleep. Furthermore, the greater the $\mathrm{LV}$ end-diastolic volume, the less the rise in $\mathrm{PaCO}_{2}$ from wakefulness to stage 2 sleep. This relationship suggests that marked LV dilatation in patients with nonischemic dilated cardiomyopathy is associated with a nonchemical respiratory drive that prevents the normal rise in $\mathrm{PaCO}_{2}$ during the transition from wakefulness to sleep. The most likely explanation for this relationship is that high LV volumes are associated with elevated LV filling pressures. These results are in line with the observation that pulmonary capillary wedge pressure was significantly greater in patients with $\mathrm{CHF}$ and Cheyne-Stokes respiration, as compared to $\mathrm{CHF}$ patients with no sleep apnea or obstructive sleep apnea. ${ }^{12}$ We have also studied CHF patients undergoing diagnostic cardiac catheterization, in which hemodynamic variables and arterial blood gases were measured simultaneously. $\mathrm{PaCO}_{2}$ correlated inversely with capillary wedge pressure ( $\mathrm{r}=-0.80, P=.003)$. In addition, in 3 patients in whom multiple measurements were made, acute alterations in capillary wedge pressure caused inversely proportional changes in $\mathrm{PaCO}_{2}{ }^{41}$ Therefore, hypocapnia in CHF patients is a respiratory manifestation of elevated LV filling pressures.

Pulmonary congestion stimulate ventilation and reduce $\mathrm{PaCO}_{2}$ by mechanisms that are not completely understood. Experiments in animals suggest that pulmonary venous congestion and elevation of interstitial pressure cause increased pulmonary vagal afferent nerve stimulation, which precipitates central apnea followed by rapid shallow ventilation with increased minute ventilation. ${ }^{42}$ These observations are limited, however, and Cheyne-Stokes was not studied. Congestive heart failure patients with Cheyne-Stokes respiration have high central and peripheral chemoresponsiviness. ${ }^{43,46,47}$ Elevated chemoreceptor responsiveness (gain) could destabilize the respiratory control system by increasing the tendency to hyperventilate, promoting both a background hypocapnia and also triggering a ventilatory overshoot. Augmented gain of the chemoreceptors, which could be primary or, more likely, secondary to pulmonary edema, destabilizes the respiratory control system by making it prone to ventilatory overshoot ${ }^{30,45}$ (Figure 2).

\section{Prolonged circulatory time}

Prolonged circulation time leading to delays in transmitting changes of arterial blood gas tensions within the lungs to the chemoreceptors could theoretically 


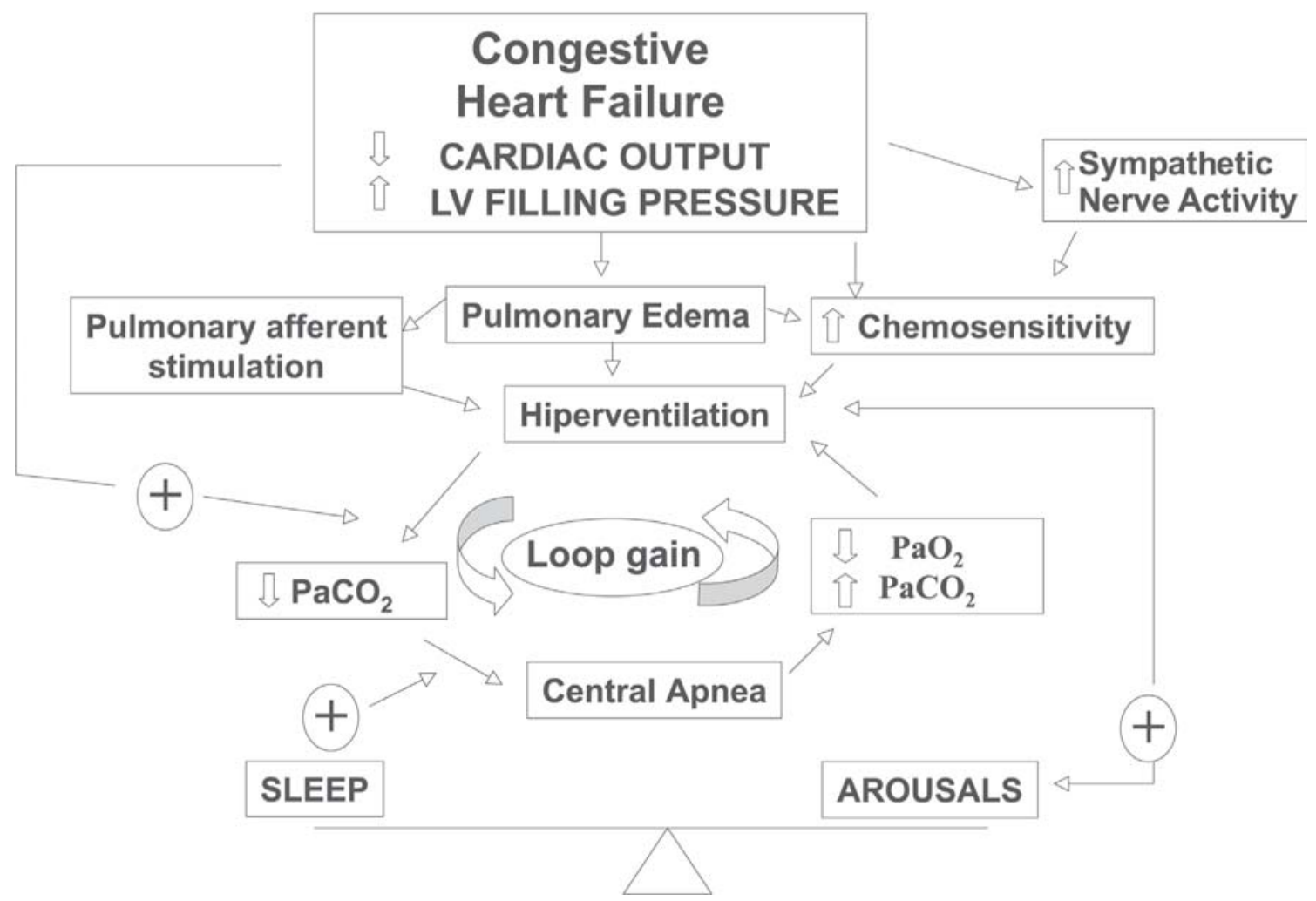

Figure 2 - Schematic representation of the mechanisms involved in the genesis of Cheyne-Stokes respiration

destabilize the respiratory control system. It could do so by changing a negative feedback into a positive feedback system such that "the right response occurs at the wrong moment". ${ }^{48,49}$ In support of this theory, Guyton et al. ${ }^{48}$ induced Cheyne-Stokes respiration in sedated dogs by inserting a length of tubing between the heart and brain to prolong the transit time from the lungs to the chemoreceptors. However, Cheyne-Stokes was achieved only when the circulatory delay was a few minutes in duration, far exceeding anything seen in patients with CHF. There is now a body of evidence indicating that prolonged circulatory delay is not the critical factor predisposing to Cheyne-Stokes respiration. In humans, the circulatory delay for a given chemical stimulus to reach the carotid body from the lungs can be estimated by determining the time from the end of an apnea until the maximum dip in $\mathrm{SaO}_{2}$ detected by an oximeter on the ear (which is in close proximity to the carotid body). This lung-to-ear circulation time (LECT) is inversely proportional to the stroke volume and cardiac output in both patients with normal and with abnormal heart function..$^{50}$ In this study, patients with idiopathic central sleep apnea (ICSA), whose cardiac function and LECT were normal, were compared to CHF patients with Cheyne-Stokes. The results showed that despite having higher stroke volumes and shorter LECT than the CHF patients with Cheyne-Stokes, those with ICSA had the same low and fluctuating $\mathrm{PaCO}_{2}$ and similar high frequencies of central apnea during sleep. These data indicate that central apneas in patients with ICSA and Cheyne-Stokes are due to hypocapnia and fluctuations in $\mathrm{PaCO}_{2}$ below and above the apnea threshold, but are not related to the degree of circulatory delay. A number of investigators have also found no significant differences in LECT or LVEF between CHF patients with and without Cheyne-Stokes respiration-..$^{21,22,3536}$ In the same study, Hall et al. observed that the longer periodic breathing cycle length in the CHF patients with Cheyne-Stokes respiration was related to a longer LECT than in the patients with idiopathic central sleep apnea. The relationship between LECT and cycle length was found to be due to the correlation of LECT and hyperpnea length, whereas LECT did not correlate with apnea length. However, the characteristic "sculpting" and prolongation of the hyperpnea in CHF patients was related to their lower cardiac output. Therefore, rather than initiating periodic breathing and central apnea, circulatory delay appears to determine hyperpnea length and, secondarily, cycle length once periodic breathing with central apnea has been established. However, it does not affect apnea length, which is influenced by the degree of preceding hyperventilation and hypocapnia. ${ }^{51}$ 


\section{Hypoxia}

One possible explanation for hyperventilation and low $\mathrm{PaCO}_{2}$ is hypoxia. Normal subjects may present periodic breathing during sleep at high altitude. In periodic breathing at high altitude, hypoxemia causes hyperventilation and lowers $\mathrm{PaCO}_{2}$ below the apnea threshold. ${ }^{52}$ Under these conditions, administration of $\mathrm{O}_{2}$ removes the hypoxic drive, allowing $\mathrm{PaCO}_{2}$ to rise above the apneic threshold and abolishing central apnea. The critical dependence of periodic breathing at high altitude on fluctuations in $\mathrm{PaCO}_{2}$ is further emphasized by the observation that $\mathrm{CO}_{2}$ inhalation, even in the presence of sustained hypoxia, raises $\mathrm{PaCO}_{2}$ and abolishes central apnea. However, both awake $\mathrm{PaO}_{2}$ and mean nocturnal $\mathrm{SaO}_{2}$ in $\mathrm{CHF}$ patients with Cheyne-Stokes respiration are within normal limits and are practically identical to those in CHF patients without Cheyne-Stokes. ${ }^{35,36,37}$ Thus, the hypoxic dips in Cheyne-Stokes respiration are the result, rather than the cause, of central apnea. Nevertheless, the hypoxic dips during apnea could further the tendency to hyperventilate at the termination of central apnea by amplifying the ventilatory response to $\mathrm{CO}_{2}$ once $\mathrm{PaCO}_{2}$ rises above the ventilatory threshold. ${ }^{30}$ Ventilatory overshoot with propagation of Cheyne-Stokes respiration would therefore be facilitated by even mild degrees of apnea-related hypoxia. Dips in $\mathrm{SaO}_{2}$ would also facilitate arousal from sleep, which in turn contributes to hyperventilation.

A number of studies have investigated the effects of supplemental oxygen in patients with $\mathrm{CHF}$ and CheyneStokes. It must be stressed that most studies were interested in abolishing the dips in $\mathrm{SaO}_{2}$ rather than understanding how such dips contribute to the genesis of Cheyne-Stokes respiration. ${ }^{53-57}$ All studies were consistent in showing small but significant reductions in the total amount of Cheyne-Stokes respiration. For instance, Hanly showed that low flow $\mathrm{O}_{2}$ administered to patients with $\mathrm{CHF}$ reduced the duration of Cheyne-Stokes respirationCSA mainly during stage 1 sleep, with no significant change during stage 2, slow wave, or rapid eye movement (REM) sleep. ${ }^{55}$ The administration of $\mathrm{O}_{2}$ was also associated with a more consolidated sleep with a decrease in the number of arousals. Modest reductions in the frequency of central apneas and hypopneas in response to $\mathrm{O}_{2}$ administration have been confirmed by others. ${ }^{54-56}$ Differences in the effects of $\mathrm{O}_{2}$ in Cheyne-Stokes respiration among patients are most likely related to rising $\mathrm{PaCO}_{2}$ in response to abolition of hypoxic drive. Taken together, these data are consistent with the concept that hypoxia may play a role in aggravating, but is not the major determinant of Cheyne-Stokes in patients with CHF.

\section{Contributing factors to respiratory instability}

Two additional factors, namely low functional residual capacity and upper airway instability may further contribute to respiratory instability and perpetuation of CheyneStokes respiration. Congestive heart failure patients have a low functional residual capacity that is further reduced by moving from the upright to the supine position. A large functional residual capacity acts as a large reservoir of $\mathrm{O}_{2}$ and $\mathrm{CO}_{2}$ in the body and damps oscillations in $\mathrm{PaO}_{2}$ and $\mathrm{PaCO}_{2}$ that would occur during apnea. ${ }^{45,58}$ Therefore, reductions in functional residual capacity decrease the lung $\mathrm{O}_{2}$ and $\mathrm{CO}_{2}$ reservoirs and allow greater reductions in $\mathrm{PaO}_{2}$ and greater increases in $\mathrm{PaCO}_{2}$ during apnea. ${ }^{45,58}$ This could contribute to instability of the respiratory control system. However, Naughton et al. ${ }^{35}$ have shown that lung volumes in CHF patients with Cheyne-Stokes respiration do not differ from those in patients without it. Thus the role of reduced lung volume in the pathogenesis of Cheyne-Stokes remains uncertain, and if present, will only help to make the respiratory system unstable.

Upper airway instability may play a role in the pathogenesis of Cheyne-Stokes. Alex et al. ${ }^{59}$ described upper airway occlusion at the onset and at the end of central apnea in patients with CHF. Instability of upper airway resistance could promote the development of respiratory instability. If upper airway resistance increases as ventilation decreases during the decrescendo phase of the hyperpneic portion of Cheyne-Stokes respiration, there will be a tendency to cause an undershoot of ventilation. ${ }^{60}$ The occasional occluded breath at the onset of central apnea during Cheyne-Stokes ${ }^{59}$ is compatible with this possibility. On the other hand, decreasing resistance as ventilation increases during the crescendo phase will facilitate overshoot, rapidly driving $\mathrm{PaCO}_{2}$ down and setting up conditions for posthyperventilation apnea. In addition, it is possible that upper airway collapse itself can reflexly precipitate central apnea. ${ }^{62}$ This suggests an important interaction between upper airway and central controller instability in the pathogenesis of some cases of Cheyne-Stokes respiration. Consistent with this hypothesis, Sahlin et al., ${ }^{63}$ studying the overnight polysomnography of 20 patients presenting Cheyne-Stokes, observed that the frequency of apneas and hypopneas in patients with this respiration was significantly higher when patients were in the supine position. It is noteworthy in this context that continuous positive airway pressure (CPAP), which dilates and stabilizes the upper airway, ${ }^{64,65}$ has been shown to alleviate CheyneStokes. ${ }^{66,67,68}$ These data must be interpreted with caution because CPAP has many other effects that could damp periodic breathing by a indirect mechanism other than 
stabilization of the upper airway. Continuous positive airway pressure is an effective treatment for the failing heart, not only because it inflates the lungs but also because it augments cardiac performance by decreasing pre and after load. ${ }^{69,70}$ On the other hand, the recent observation that Cheyne-Stokes respiration is more frequent in the supine position is compelling evidence that upper airway instability does play a role in the aggravation of the respiration, at least in some patients.

\section{CONSEQUENCES OF CHEYNE-STOKES RESPIRATION}

Cheyne-Stokes respiration is the consequence of a failing heart. Accordingly, Cheyne-Stokes is ameliorated by therapies that improve myocardial function, such as cardiac resynchronization in patients with $\mathrm{CHF}$ associated with conduction disturbances, ${ }^{71}$ and goes away after heart transplant. ${ }^{72}$ One important question raised is: once established, does Cheyne-Stokes respiration constitute an additional burden to the patient? It is now recognized that it gives rise to clinical problems largely through its effects during sleep, in agreement with the observations of Harrison et al. ${ }^{73}$ These effects are similar to those associated with sleep apnea syndromes and lead to disrupted sleep and its consequences. Hanly et al. ${ }^{74}$ showed that patients with CHF and CheyneStokes had a sleep latency that was significantly shorter than CHF patients without this breathing disorder, suggesting that they suffered from hypersomnolence. In addition, they demonstrated that patients with CHF and CheyneStokes had more stage 1 and 2 nonREM sleep, less REM sleep, and a higher frequency of arousals from sleep than CHF patients without the breathing disorder. ${ }^{72}$ Interestingly enough, $\mathrm{CHF}$ patients with Cheyne-Stokes respiration ${ }^{14}$ and obstructive sleep apnea ${ }^{75}$ do not complain of significant subjective sleepiness. The symptoms may overlap with the fatigue that is characteristic in patients with severe CHF.

There is some evidence suggesting that Cheyne-Stokes respiration is a marker of poor prognosis in patients with $\mathrm{CHF}$, but the data is conflicting. Findley et al. reported in an uncontrolled retrospective study that patients with CHF who also suffered from Cheyne-Stokes during sleep had a higher mortality rate than patients without it. Hanly et al. ${ }^{22}$ prospectively followed a group of 16 patients with stable CHF, 9 of whom had Cheyne-Stokes respiration and 7 of whom did not. Despite comparable LVEF, the combined rate of mortality and heart transplantation was significantly higher in the CheyneStokes group. Similarly, Sin et al. ${ }^{23}$ observed an increased mortality in CHF patients presenting Cheyne-Stokes respiration. These data suggest that Cheyne-Stokes itself may accelerate disease progression in patients with heart failure.
Conversely, Andreas et al. ${ }^{73}$ did not observe increased mortality in patients presenting Cheyne-Stokes respiration during the night, but only in patients presenting it while awake. Rebuck et al. followed 78 patients, of whom $42 \%$ had Cheyne-Stokes, over a median period of 52 months. The authors were able to confirm an increased mortality in patients presenting sleep disorder breathing (including obstructive sleep apnea, present in 28\%) at 500 days, but contrary to their initial hypothesis, the effect was lost at long-term follow-up (52 months). ${ }^{77}$ Therefore, the effects of Cheyne-Stokes respiration during sleep in patients with $\mathrm{CHF}$ remain to be established. It is possible that respiratory instability while awake is more meaningful for mortality than while asleep. Supporting this hypothesis, we have observed that periodic breathing during exercise (a mild form of Cheyne-Stokes) was a powerful predictor of mortality in CHF patients waiting for heart transplant. ${ }^{3}$

Regardless of the exact impact of Cheyne-Stokes on mortality, there is evidence that it may be detrimental to the failing heart. Blood pressure (BP) and heart rate (HR) oscillate in concert with Cheyne-Stokes cycles, very much as they do during obstructive sleep apnea; that is, peaks occur during the hypernea and troughs during apnea. ${ }^{56,78}$ These oscillations could be related to the same mechanisms that have been implicated in obstructive sleep apnea, including hypoxia and arousals from sleep, both of which can stimulate sympathetic nerve activity. However, Franklin et al. and Leung et al. ${ }^{20}$ found that $\mathrm{O}_{2}$ administration at a sufficient flow rate to abolish dips in $\mathrm{SaO}_{2}$ did not significantly influence BP or HR oscillations during Cheyne-Stokes respiration. These data indicate that mechanisms other than hypoxic dips are involved in precipitating these surges in BP and HR during Cheyne-Stokes. The best explanation for the oscillations in BP and HR during Cheyne-Stokes is related to the intrinsic link between ventilation and the cardiovascular system, which, for instance, also produces oscillations in BP and HR on a breath-to-breath basis. Normal subjects voluntarily reproducing a Cheyne-Stokes respiratory pattern of breathing (in the absence of hypoxia or arousals from sleep) presented profound oscillations in BP and HR in a pattern that was similar to what is seen in CHF patients during Cheyne-Stokes respiration. ${ }^{18}$ Trinder et al. ${ }^{75}$ also found that BP oscillations during Cheyne-Stokes in $\mathrm{CHF}$ were related to oscillations in ventilation and not to the level of hypoxia. Moreover, when Cheyne-Stokes was abolished by the inhalation of small concentrations of $\mathrm{CO}_{2}$, oscillations in BP and HR were also abolished. ${ }^{20}$ Regardless of the exact mechanisms, once established, CheyneStokes promotes cyclic increases in BP and HR in concert with the ventilatory cycle, ${ }^{20,56,78}$ which may contribute to a poor prognosis for CHF patients with Cheyne-Stokes. 
Hypoxia and arousals from sleep present during CheyneStokes may also be associated with stimulation of the sympathetic nervous system. Overnight urinary norepinephrine concentrations and daytime plasma norepinephrine concentrations are markedly higher in CHF patients with CheyneStokes than in those without it, and they are directly related to the frequency of arousals from sleep and to the degree of apnea-related hypoxia, but not to left ventricular ejection fraction. ${ }^{79}$ These data suggest that Cheyne-Stokes can trigger sympathetic activation in patients with CHF. These higher nocturnal and daytime catecholamine concentrations might aggravate myocardial dysfunction. On the other hand, Mansfield et al. ${ }^{80}$ studied $55 \mathrm{CHF}$ patients and showed that Cheyne-Stokes breathing was associated with worse cardiac function (higher mean pulmonary artery pressure) and higher total body plasma and cardiac norepinephrine. The differences in norepinephrine were due to heart failure and not to apnea severity. Cheyne-Stokes respiration could therefore be a marker of poor prognosis rather than a causative factor. This hypothesis fits with the observation that $\mathrm{CHF}$ patients with this breathing disorder have larger left ventricles than those without it. ${ }^{81}$ Javaheri et al. also observed that Cheyne-Stokes is associated with a lower $\mathrm{PaCO}_{2}$ and a higher rate of ventricular tachycardia. ${ }^{37}$ These associations do not clarify whether there is any relationship of causality between Cheyne-Stokes and poor prognosis, and further studies are needed.

The discussion of the treatment of Cheyne-Stokes respi- ration in patients with $\mathrm{CHF}$ is beyond the scope of this review. Readers wishing an in depth discussion of this subject are referred to a recent review. ${ }^{82}$ Briefly, since Cheyne-Stokes respiration probably arises from $\mathrm{CHF}$, the first approach to therapy is to optimize the medical therapy of CHF. ${ }^{83}$ Failing that, there are a number of other therapeutic options. The most extensively tested intervention is CPAP. When used overnight for 1 to 3 months, CPAP has been shown to alleviate CheyneStokes; to increase LVEF; reduce mitral regurgitation, atrial natriuretic peptide and both urinary and plasma norepinephrine levels. It also improved quality of life and survival. $^{23,67,68,79,84,85}$ Oxygen administration has been shown to cause a modest reduction in the severity of Cheyne-Stokes respiration, to reduce overnight urinary norepinephrine levels, and cause an increase in peak $\mathrm{O}_{2}$ consumption during graded exercise over periods of 1 to 4 weeks. ${ }^{53-57}$ Finally, theophylline has been shown to reduce the severity of CheyneStokes over 5 days, but has not been shown to improve cardiac function, neurohumoral activity, or quality of life. ${ }^{86}$ Pepperell et al. have recently shown in a prospective randomized trial that 1 month of nocturnal-assist servoventilation was able to reduce daytime sleepiness in conjunction with improvements in plasma brain natriuretic peptide and urinary metadrenaline excretion in patients with $\mathrm{CHF}$ and Cheyne-Stokes. ${ }^{87}$ Larger, longer-term randomized trials will be required to determine which, if any, of these interventions are effective for the management of CHF patients with Cheyne-Stokes respiration. ${ }^{88}$

\section{RESUMO}

Lorenzi-Filho G, Genta PR, Figueiredo AC, Inoue D. A respiração de Cheyne-Stokes em pacientes com insuficiência cardíaca congestiva: causas e conseqüências. Clinics. 2005;60(4): 333-44.

A respiração de Cheyne-Stokes é uma forma de respiração periódica na qual apnéias e hipopnéias se alternam com períodos de hiperpnéias que apresentam um padrão crescendo e decrescendo de volume corrente. Esta revisão enfoca as causa e conseqüências da respiração de Cheyne-
Stokes em pacientes com insuficiência cardíaca congestiva na qual a prevalência é extremamente alta e varia entre 30 a 50\%. Vários fatores foram implicados na gênese da respiração de Cheyne-Stokes, incluindo baixo debito cardíaco e hipoxia recorrente. Hiperventilacão e baixos níveis de $\mathrm{CO} 2$ arterial (PaCO2), que quando abaixo do limiar de apnéia desencadeiam apnéia central são os mecanismos fisiopatológicos chave na gênese da respiração de Cheyne-Stokes. Hiperventilação está associada com congestão pulmonar, e a respiração de Cheyne-Stokes tem 
uma tendência maior de ocorrer durante o sono, quando o centro respiratório é dependente principalmente do controle químico. A respiração de Cheyne-Stokes está associada a quedas recorrentes da saturação de oxigênio e ao despertar do sono, com oscilações recorrentes na freqüência cardíaca, pressão arterial, aumento da atividade simpática e risco aumentado de taquicardia ventricular. A respiração de
Cheyne-Stokes é um marcador independente de mau prognostico e provavelmente participa de um ciclo vicioso que contribui para a deterioração cardíaca.

UNITERMOS: Respiração de Cheyne-Stokes. Insuficiência cardíaca congestiva. Sono. Controle da ventilação. Apnéia central.

\section{REFERENCES}

1. Tobin JM, Snyder JV. Cheyne-Stokes respiration revisited: Controversies and implications. Critical Care Medicine. $1984 ; 12(10): 882-7$

2. Mithoefer JC, Bossman OG, Thibeault DW, Mead GD. The clinical estimation of alveolar ventilation. Am Rev Respir Dis. 1968;98:868.

3. Leite JJ, Mansur AJ, de Freitas HF, Chizola PR, Bocchi EA, TerraFilho M, et al. Periodic breathing during incremental exercise predicts mortality in patients with chronic heart failure evaluated for cardiac transplantation. J Am Coll Cardiol. 2003 Jun $18 ; 41(12): 2175-81$

4. Lorenzi-Filho G, Bradley TD. Cardiac function in sleep apnea. In Sleep Apnea. Pathogenesis, Diagnosis, and Treatment. Pack AI. Marcel Dekker, Inc. 2002:377-410.

5. Cheyne J. A case of apoplexy in which the fleshy part of the heart was converted to fat. Dublin Hospital Reports. 1818;2:216-23.

6. Stokes W: The Diseases of the Heart and the Aorta. Dublin, Hodges and Smith, 1854, p. 302-40.

7. Bradley TD, Floras JS. Pathophysiologic and therapeutic implications of sleep apnea in congestive heart failure. J Card Fail. 1996;2:223-40.

8. Hanly PJ, Millar TW, Steljes DG, Baert R, Frais MA, Kryger MH. Respiration and abnormal sleep in patients with congestive heart failure. Chest. 1989;96:480-8.

9. Dowdell WT, Javaheri S, McGinnis W. Cheyne-Stokes respiration presenting as sleep apnea syndrome. Clinical and polysomnographic features. Am Rev Respir Dis. 1990;141:871-9.
10. Javaheri S, Parker TJ, Wexler L, Michaels SE, Stanberry E, Nishyama H, et al. Occult sleep-disordered breathing in stable congestive heart failure. Ann Intern Med. 1995;122:487-92.

11. Javaheri S, Parker TJ, Liming JD, Corbett WS, Nishiyama H, Wexler $\mathrm{L}$, et al. Sleep apnea in 81 ambulatory male patients with stable heart failure. Types and their prevalences, consequences, and presentations. Circulation. 1998 Jun 2;97(21):2154-9.

12. Solin P, Bergin P, Richardson M, Kaye DM, Walters EH, Naughton MT Influence of pulmonary capillary wedge pressure on central apnea in heart failure. Circulation. 1999 Mar 30;99(12):1574-9.

13. Sin DD, Fitzgerald F, Parker JD, Newton G, Floras JS, Bradley TD. Risk factors for central and obstructive sleep apnea in 450 men and women with congestive heart failure. Am J Respir Crit Care Med. 1999 Oct;160(4):1101-6.

14. Silva RS, Alves RC, Mady C, Lorenzi-filho G. Breathing Disorders in patients with congestive heart failure. Sleep. vol 24, April 15, 2001:A291.

15. Prevalência de distúrbios respiratórios do sono em pacientes ambulatoriais com insuficiência cardíaca. Tese apresentada à Faculdade de Medicina da Universidade de São Paulo para obtenção do titulo de doutor em ciências Área de concentração: Fisiopatologia Experimental São Paulo - 2003 USP7FM/SDB$508 / 03$.

16. Tkacova R, Niroumand M, Lorenzi-Filho G, Bradley TD. Overnight shift from obstructive to central apneas in patients with heart failure: role of $\mathrm{PCO}_{2}$ and circulatory delay. Circulation. 2001;103(2):23843. 
17. Ryan CM, Bradley TD. Periodicity of obstructive sleep apnea in patients with and without heart failure. Chest. 2005;127(2):53642 .

18. Lorenzi-Filho G, Dajani HR, Leung RS, Floras JS, Bradley TD. Entrainment of blood pressure and heart rate oscillations by periodic breathing. Am J Respir Crit Care Med. 1999;159:1147-54.

19. Leung RS, Floras JS, Lorenzi-Filho G, Rankin F, Picton P, Bradley TD. Influence of Cheyne-Stokes respiration on cardiovascular oscillations in heart failure. Am J Respir Crit Care Med. 2003;167(11):1534-9.

20. Leung RS, Diep TM, Bowman ME, Lorenzi-Filho G, Bradley TD. Provocation of ventricular ectopy by Cheyne-Stokes respiration in patients with heart failure. Sleep. 2004;27(7):1337-43.

21. Findley LJ, Zwillich CW, Ancoli-Israel S, Kripke D, Tisi G, Moser KM. Cheyne-Stokes breathing during sleep in patients with left ventricular heart failure. South Med J. 1985;78:11-5.

22. Hanly PJ, Zuberi-Khokhar NS. Increased mortality associated with Cheyne-Stokes respiration in patients with congestive heart failure. Am J Respir Crit Care Med. 1996;153:272-6.

23. Sin DD, Logan AG, Fitzgerald FS, Liu PP, Bradley TD. Effects of continuous positive airway pressure on cardiovascular outcomes in heart failure patients with and without Cheyne-Stokes respiration. Circulation. 2000 Jul 4;102(1):61-6.

24. Bradley TD Lorenzi-Filho,G, Floras JS. Pathophysiological Interactions Between Sleep Apnea and the Heart. In Respiratorycirculatory Interactions in Health and Disease. Scharf SM, Pinsky MR, Magder S. Marcel Dekker, Inc. 2001: 577-611.

25. Leung RS, Bradley TD. Sleep apnea and cardiovascular disease. Am J Respir Crit Care Med. 2001 Dec 15;164(12):2147-65.

26. Bradley TD, Floras JS. Sleep apnea and heart failure: Part II: central sleep apnea. Circulation. 2003 Apr 8;107(13):1822-6.

27. Bradley TD, Floras JS. Sleep apnea and heart failure: Part I: obstructive sleep apnea. Circulation. 2003 Apr 1;107(12):1671-8.

28. Daly MDB. Interactions between respiration and circulation. In: Cherniack NS, Widdicombe JG, editors. Handbook of Physiology. 3rd ed. Bethesda: American Physiological Society, 1986:529-594.

29. Bradley TD, Phillipson EA. Central sleep apnea. Clin Chest Med. 1992;13:493-505

30. Khoo MC, Kronauer RE, Strohl KP, Slutsky AS. Factors inducing periodic breathing in humans: a general model. J Appl Physiol. 1982;53:644-59.

31. Skaturd JB, Dempsey JA. Interaction of sleep state and chemical stimuli in sustaining rhythmic ventilation. J Appl Physiol. 1983; $55: 813-22$.

32. Phillipson EA. Control of breathing during sleep. Am Rev Respir Dis. 1978;118:909-39.

33. Xie A, Wong B, Phillipson EA, Slutsky AS, Bradley TD. Interaction of hyperventilation and arousal in the pathogenesis of idiopathic central sleep apnea. Am J Respir Crit Care Med. 1994;150:489-95.

34. Bradley TD, Floras JS. Pathophysiologic and therapeutic implications of sleep apnea in congestive heart failure. J Card Fail. $1996 ; 2: 223-40$
35. Naughton M, Benard D, Tam A, Rutherford R, Bradley TD. Role of hyperventilation in the pathogenesis of central sleep apneas in patients with congestive heart failure. Am Rev Respir Dis. $1993 ; 148: 330-8$

36. Hanly P, Zuberi N, Gray R. Pathogenesis of Cheyne-Stokes respiration in patients with congestive heart failure. Relationship to arterial $\mathrm{PCO}_{2}$. Chest. 1993;104:1079-84.

37. Javaheri S, Corbett WS. Association of low $\mathrm{PaCO}_{2}$ with central sleep apnea and ventricular arrhythmias in ambulatory patients with stable heart failure. Ann Intern Med. 1998;128:204-7.

38. Tkacova R, Hall ML, Liu PP, Fitzgerald FS, Bradley TD. Left ventricular volumes in patients with heart failure and Cheyn-Stokes respiration during sleep. Am J Respir Crit Care Med. 1997; 156:1549-55.

39. Xie A, Skatrud JB, Puleo DS, Rahko PS, Dempsey JA. Apneahypopnea threshold for $\mathrm{CO}_{2}$ in Patients with congestive heart failure. Am J Respir Crit Care Med. 2002;1651245-50.

40. Lorenzi-Filho G, Rankin F, Bies I, Douglas Bradley T. Effects of inhaled carbon dioxide and oxygen on Cheyne-Stokes respiration in patients with heart failure. Am J Respir Crit Care Med. 1999; $159: 1490-8$

41. Lorenzi-Filho G, Azevedo ER, Parker JD, Bradley TD. Relationship of $\mathrm{PaCO}_{2}$ to pulmonary wedge pressure in heart failure. Eur Respir J. $2002 ; 19(1): 37-40$

42. Churchill ED, Cope O. The rapid shallow breathing resulting from pulmonary congestion and edema. J Exper Med. 1929;49:531-7.

43. Wilcox I, Grunstein RR, Collins FL, Berthon-Jones M, Kelly DT, Sullivan CE. The role of central chemosensitivity in central apnea of heart failure. Sleep. 1993;16:S37-S38.

44. Ahmed M, Serrette C, Kryger MH, Anthonisen NR. Ventilatory instability in patients with congestive heart failure and nocturnal Cheyne-Stokes breathing. Sleep. 1994;17:527-34.

45. Cherniack NS, Longobardo GS. Cheyne-Stokes breathing. An instability in physiologic control. N Engl J Med. 1973;288:952-7.

46. Solin P, Roebuck T, Johns DP, Walters EH, Naughton MT. Peripheral and central ventilatory responses in central sleep apnea with and without congestive heart failure. Am J Respir Crit Care Med. 2000 Dec;162(6):2194-200.

47. Javaheri S. A mechanism of central sleep apnea in patients with heart failure. N Engl J Med. 1999 Sep 23;341(13):949-54.

48. Guyton AC, Crowell JW, Moore JW. Basic oscillating mechanism of Cheyne-Stokes breathing. Am J Physiol. 1956;187:395-8.

49. Francis DP, Willson K, Davies LC, Coats AJ, Piepoli M. Quantitative general theory for periodic breathing in chronic heart failure and its clinical implications. Circulation. 2000 Oct 31;102(18):221421.

50. Hall MJ, Xie A, Rutherford R, Ando S, Floras JS, Bradley TD. Cycle length of periodic breathing in patients with and without heart failure. Am J Respir Crit Care Med. 1996;154:376-81.

51. Datta AK, Shea AA, Horner RL, Guz A. The influence of induced hypocapnia and sleep on the endogenous respiratory rhythm in humans. J Physiol (Lond). 1991;440:17-33. 
52. Berssenbrugge A, Dempsey J, Iber C, Skatrud J, Wison P. Mechanisms of hypoxia-induced periodic breathing during sleep in humans. J Physiol (Lond). 1983;343:507-24.

53. Franklin KA, Eriksson P, Sahlin C, Lundgren R. Reversal of central sleep apnea with oxygen. Chest. 1997;111:163-9.

54. Andreas S, Clemens C, Sandholzer H, Figulla HR, Kreuzer H. Improvement of exercise capacity with treatment of Cheyne-Stokes respiration in patients with congestive heart failure. J Am Coll Cardiol. 1996;27:1486-90.

55. Hanly PJ, Millar TW, Steljes DG, Baert R, Frais MA, Kryger MH. The effect of oxygen on respiration and sleep in patients with congestive heart failure. Ann Intern Med. 1989;111:777-82.

56. Franklin KA, Sandstrom E, Johansson G, Balfors EM. Hemodynamics, cerebral circulation, and oxygen saturation in Cheyne-Stokes respiration. J Appl Physiol. 1997;83:1184-91.

57. Staniforth AD, Kinnear WJM, Starling R, Hetmanski DJ, Cowley AJ. Effect of oxygen on sleep quality, cognitive function, and sympathetic activity in patients with chronic heart failure and Cheyne-Stokes respiration. Eur Heart J. 1998;19:922-8.

58. Longobardo GS, Cherniack NS, Fishman AP. Cheyne-Stokes breathing produced by a model of the human respiratory system. J Appl Physiol. 1966;21:1839-46.

59. Alex CG, Onal E, Lopata M. Upper airway occlusion during sleep in patients with Cheyne-Stokes respiration. Am Rev Respir Dis. 1986;133:42-5.

60. Dempsy JA, Smith CA, Harms CA, Chow C, Saupe KW. Induced breathing instability. Sleep. 1996;19(3):236-247.

61. Younes M. The physiologic basis of central apnea and periodic breathing. Current Pulmonology. 1989;10:265-326.

62. Sullivan CE, Murphy E, Kozar LF. Waking and ventilatory responses to laryngeal stimulation in sleeping dogs. J Appl Physiol. 1978;45:681-9.

63. Sahlin C, Svanborg E, Stenlund H, Franklin KA. Cheyne-Stokes respiration and supine dependency. Eur Respir J. 2005 May;25(5):829-33.

64. Bradley TD, Brown IG, Grossman RF, Zamel N, Martinez D, Phillipson EA, et al. Pharyngeal size in snorers, nonsnorers, and patients with obstructive sleep apnea. N Engl J Med. 1986;315:1327-31.

65. Sullivan CE, Issa FG, Berthon-Jones M, Eves L. Reversal of obstructive sleep apnea by continuous positive airway pressure applied through the nares. Lancet. 1981;1:862-865.

66. Issa FG, Sullivan CE. Reversal of central sleep apnea using nasal CPAP. Chest. 1986;90:165-71.

67. Takasaki Y, Orr D, Popkin J, Rutherford R, Liu P, Bradley TD. Effect of nasal continuous positive airway pressure on sleep apnea in congestive heart failure. Am Rev Respir Dis. 1989;140:157884

68. Naughton MT, Liu PP, Bernard DC, Goldstein RS, Bradley TD. Treatment of congestive heart failure and Cheyne-Stokes respiration during sleep by continuous positive airway pressure. Am J Respir Crit Care Med. 1995;151:92-7.
69. Park M, Lorenzi-Filho G, Feltrim MI, Viecili PR, Sangean MC, Volpe M, et al. Oxygen therapy, continuous positive airway pressure, or noninvasive bilevel positive pressure ventilation in the treatment of acute cardiogenic pulmonary edema. A rq Bras Cardiol. 2001 Mar;76(3):221-30.

70. Park M, Sangean MC, Volpe Mde S, Feltrim MI, Nozawa E, Leite $\mathrm{PF}$, et al. Randomized, prospective trial of oxygen, continuous positive airway pressure, and bilevel positive airway pressure by face mask in acute cardiogenic pulmonary edema. Crit Care Med. 2004 Dec;32(12):2407-15.

71. Sinha AM, Skobel EC, Breithardt OA, Norra C, Markus KU, Breuer $\mathrm{C}$, et al. Cardiac resynchronization therapy improves central sleep apnea and Cheyne-Stokes respiration in patients with chronic heart failure. J Am Coll Cardiol. 2004 Jul 7;44(1):68-71.

72. Mansfield DR, Solin P, Roebuck T, Bergin P, Kaye DM, Naughton MT The effect of successful heart transplant treatment of heart failure on central sleep apnea. Chest. 2003 Nov;124(5):1675-81.

73. Harrison TR, King CE, Calhoun JA, Harrison WG. Cheyne-Stokes respiration as the cause of paroxysmal dyspnea at the onset of sleep. Arch Int Med. 1934;53:891-910.

74. Hanly P, Zuberi-Khokhar N. Daytime sleepiness in patients with congestive heart failure and Cheyne-Stokes respiration. Chest. 1995;107:952-8.

75. Kaneko Y, Floras JS, Usui K, Plante J, Tkacova R, Kubo T, et al. Cardiovascular effects of continuous positive airway pressure in patients with heart failure and obstructive sleep apnea. N Engl J Med. 2003 Mar 27;348(13):1233-41.

76. Andreas S, Hagenah G, Moller C, Werner GS, Kreuzer H. CheyneStokes respiration and prognosis in congestive heart failure. Am J Cardiol. 1996;78:1260-4.

77. Roebuck T, Solin P, Kaye DM, Bergin P, Bailey M, Naughton MT Increased long-term mortality in heart failure due to sleep apnoea is not yet proven. Eur Respir J. 2004 May;23(5):735-40.

78. Trinder J, Merson R, Rosenberg JI, Fitzgerald F, Kleiman J, Bradley TD. Pathophysiological interactions of ventilation, arousals, and blood pressure oscillations during Cheyne-Stokes respiration in patients with heart failure. Am J Respir Crit Care Med. 2000 Sep;162(3 Pt 1):808-13.

79. Naughton MT, Benard DC, Liu PP, Rutherford R, Rankin F, Bradley TD. Effects of nasal CPAP on sympathetic activity in patients with heart failure and central sleep apnea. Am J Respir Crit Care Med. 1995;152:473-9.

80. Mansfield D, Kaye DM, Brunner La Rocca H, Solin P, Esler MD, Naughton MT. Raised sympathetic nerve activity in heart failure and central sleep apnea is due to heart failure severity. Circulation. 2003 Mar 18;107(10):1396-400.

81. Tkacova R, Hall MJ, Liu PP, Fitzgerald FS, Bradley TD. Left ventricular volume in patients with heart failure and Cheyne- Stokes respiration during sleep. Am J Respir Crit Care Med. 1997; $156: 1549-55$

82. Naughton MT, Bradley TD. Sleep apnea in congestive heart failure. Clin Chest Med. 1998;19:99-113.

83. Dark DS, Pingleton SK, Kerby GR, Crabb JE, Gollub SB, Glatter TR, et al. Breathing pattern abnormalities and arterial oxygen desaturation during sleep in the congestive heart failure syndrome. Improvement following medical therapy. Chest. 1987;91:833-6. 
84. Granton JT, Naughton MT, Benard DC, Liu PP, Goldstein RS, Bradley TD. CPAP improves inspiratory muscle strength in patients with heart failure and central sleep apnea. Am J Respir Crit Care Med. 1996;153:277-82.

85. Tkacova R, Liu PP, Naughton MT, Bradley TD. Effect of continuous positive airway pressure on mitral regurgitant fraction and atrial natriuretic peptide in patients with heart failure. J Am Coll Cardiol. 1997;30:739-45.

86. Javaheri S, Parker TJ, Wexler L, Liming JD, Lindower P, Roselle GA. Effect of theophylline on sleep-disordered breathing in heart failure. N Engl J Med. 1996;335:562-7.
87. Pepperell JC, Maskell NA, Jones DR, Langford-Wiley BA, Crosthwaite N, Stradling JR, et al. A randomized controlled trial of adaptive ventilation for Cheyne-Stokes breathing in heart failure. Am J Respir Crit Care Med. 2003 Nov 1;168(9):1109-14.

88. Bradley TD, Logan AG, Floras JS; CANPAP Investigators. Rationale and design of the Canadian Continuous Positive Airway Pressure Trial for Congestive Heart Failure Patients with Central Sleep Apnea-CANPAP. Can J Cardiol. 2001 Jun;17(6):677-84. 